\title{
RadWatch Near-Realtime Air Monitoring (Natural Radioactive Backgrounds and Outreach)
}

\author{
Ryan Pavlovsky
}

\begin{abstract}
Radioactive backgrounds establish the limit of sensitivity in detection systems for the general search scenario, and set the reasonably unavoidable dose limits for members of the public. Measurement of NORM isotopes in the air provides a unique opportunity to serve the dual goals of capturing temporal/ meteorological NORM variations as well as coordinate public outreach/education of NORM exposure. The RadWatch Near-Realtime Air Monitor (RAM) stores meteorological and high resolution spectroscopy data as a function of time from six stories above UC Berkeley Campus. This data is served hourly to the public via radwatch.berkeley.edu/airsampling to demonstrate, not only the existence of NORM, but also the large variations observed in radioisotope air concentration. Clarity and transparency in this education effort are paramount, and complement the urgency of a 'realtime' system. In the future RadWatch will expand to interactive, networked devices to broaden the scope and engage the public.
\end{abstract}

Keywords NORM • Background radiation · Radon · Low dose $\cdot$ Outreach

\section{Introduction}

Currently there exists a major deficit in public knowledge about nuclear technologies and nuclear science. A resilient society will include the education of the public and will be crucial to the success of nuclear technologies. The RadWatch program seeks to fill those gaps by providing data in context for background radiation measurements around the Bay Area. Here transparency and clarity

\footnotetext{
R. Pavlovsky ( $\square)$

Etcheverry Hall, University of California, Berkeley, USA

e-mail: rp@ berkeley.edu 
measurements/data are paramount. A branch of the RadWatch activities, the Near-Realtime Air Monitor (RAM) is crucial to public outreach efforts and serves the dual purpose of providing high resolution spectroscopy data to analyze temporal and meteorological inputs on variations in the natural radioactive background.

\section{Near-Realtime Air Monitor Detection Scheme}

The air monitor that we have constructed forces 21SCFM of air through a 4" diameter HEPA filter which is continuously assayed by a high resolution gamma spectrometer (HPGe). The FPAE-102 filter collects $99.99 \%$ DOP $0.3 \mu \mathrm{m}$ particles. The mechanically cooled, n-type HPGe detector has superior energy resolution and efficiency, even at $\sim 10 \mathrm{keV}$ energies. The detector is sensitive in the $3-3000 \mathrm{keV}$ energy range. Spectra are reported every hour to the public to promote transparency (Figs. 1 and 2).

Fig. 1 RAM system, acquisition and weather station electronics

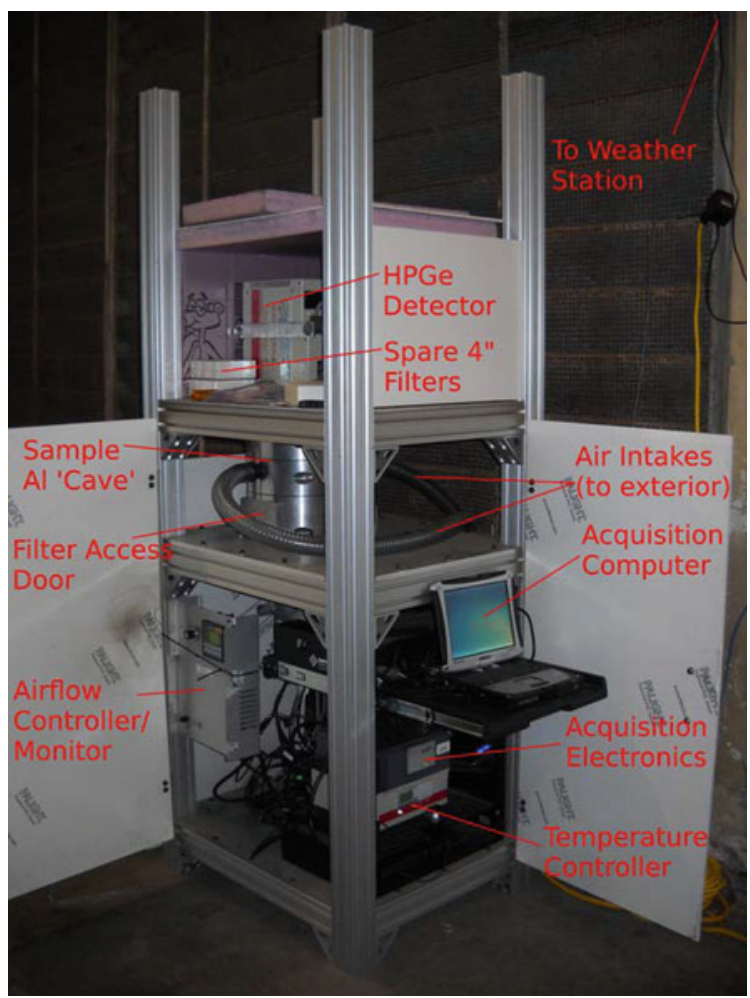




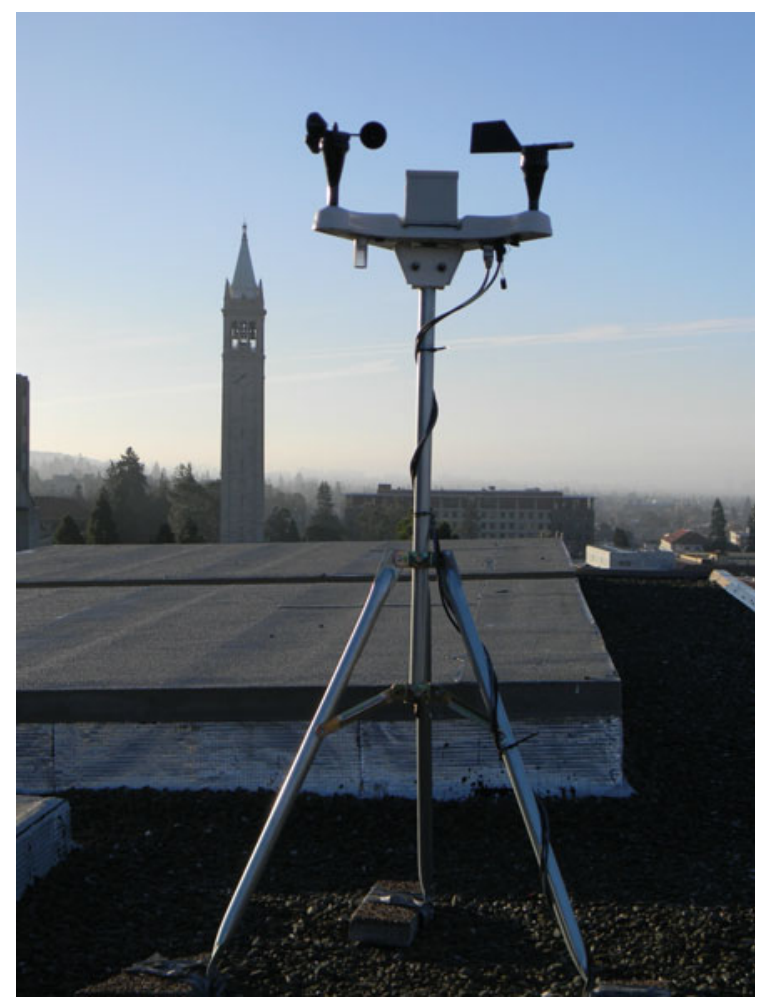

Fig. 2 Weather station with 6 parameters of local meteorological data, about $25 \mathrm{~m}$ above street level

\section{Radioisotopes of Interest}

Isotopes reported by RAM are primarily selected by total contribution to the spectra. These lines are NORM materials, composed of ${ }^{40} \mathrm{~K},{ }^{238} \mathrm{U},{ }^{232} \mathrm{Th}$ or their daughters. Specifically thoron and radon daughters are of interest because they provide almost $2 / 3$ of the natural dose that healthy individuals receive. Other isotopes are of public interest after events such as Fukushima Dai'ichi which include residual fallout or TENORM. The RAM is an improvement over the previous revision of the sample based air monitors that we employed just after Fukushima. The measurements for the time period just after Fukushima were mainly focused on the detection of ${ }^{134} \mathrm{Cs}$ and ${ }^{137} \mathrm{Cs}$, the results are provided in Fig. 5 (Figs. 3, 4 and 6). 


\begin{tabular}{|c|c|}
\hline \hline Isotope & Origin \\
\hline Bi214 & Naturally Occurring(U238) \\
\hline $\mathrm{Pb} 212$ & Naturally Occurring(Th232) \\
\hline $\mathrm{T} 1208$ & Naturally Occurring(Th232) \\
\hline $\mathrm{K} 40$ & Naturally Occurring \\
\hline $\mathrm{Cs} 134$ & Reactor \\
\hline $\mathrm{Cs} 137$ & Technically Enchanced/Naturally Occurring \\
\hline \hline
\end{tabular}

Fig. 3 The isotopes reported by the RAM system to the web. These are significant in that they are NORM or isotopes related to Fukushima releases

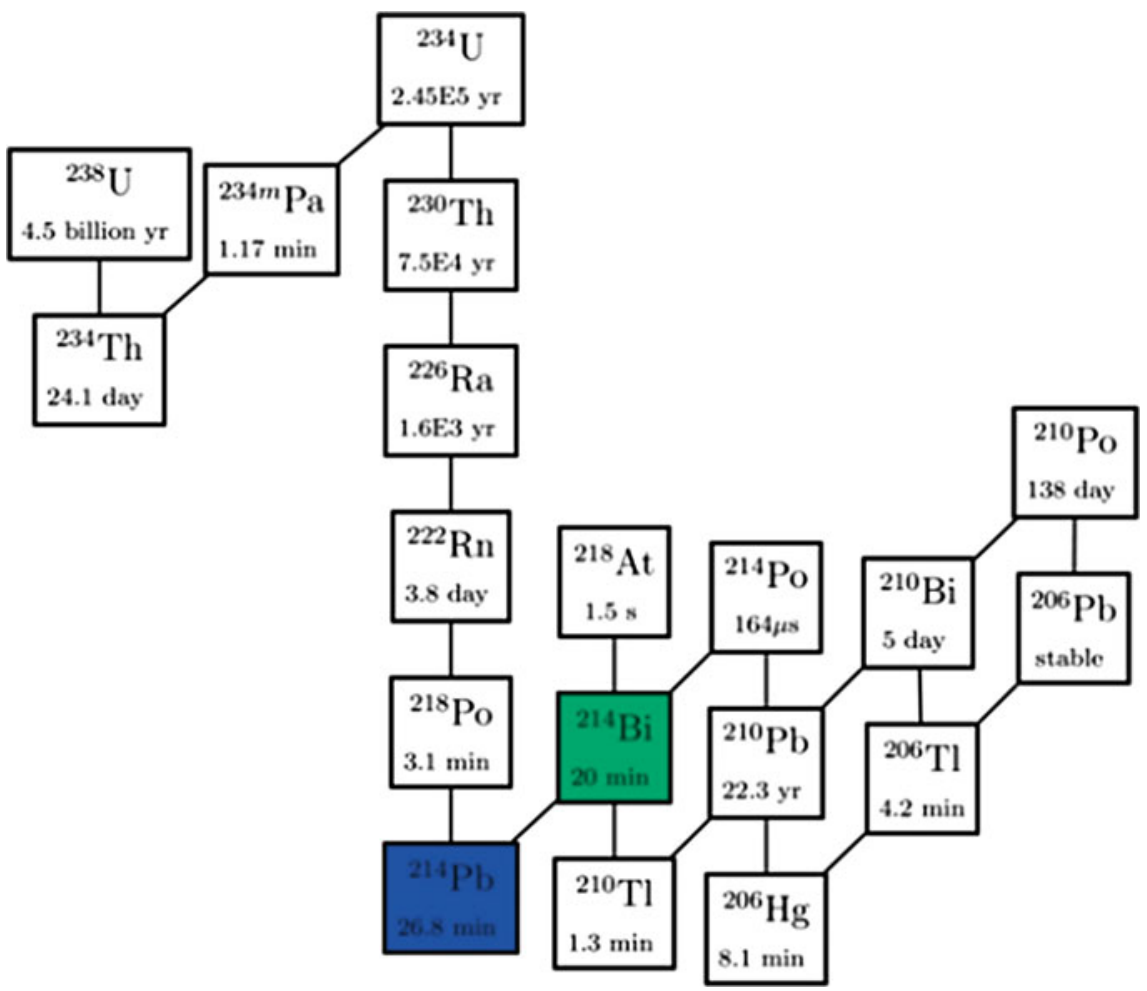

Fig. 4 238U decay chain. These decays constitute the majority of the public's dose 


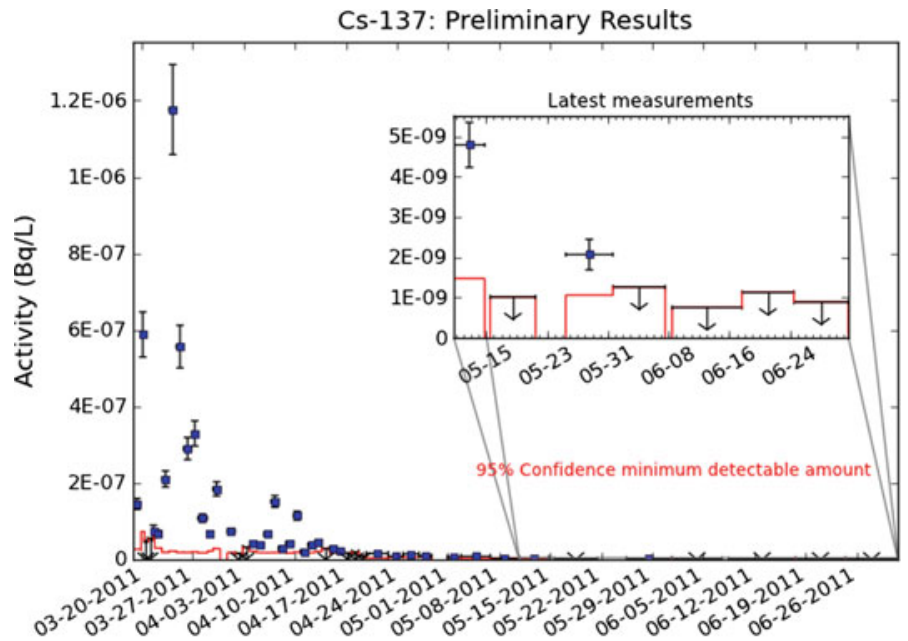

Date Collected

Fig. $5{ }^{137} \mathrm{Cs}$ and ${ }^{134} \mathrm{Cs}$ discrete filter air sampling just after Fukushima with first revision air sampler. The RAM system would have the ability to continuously sample events of this kind, capturing the transient response

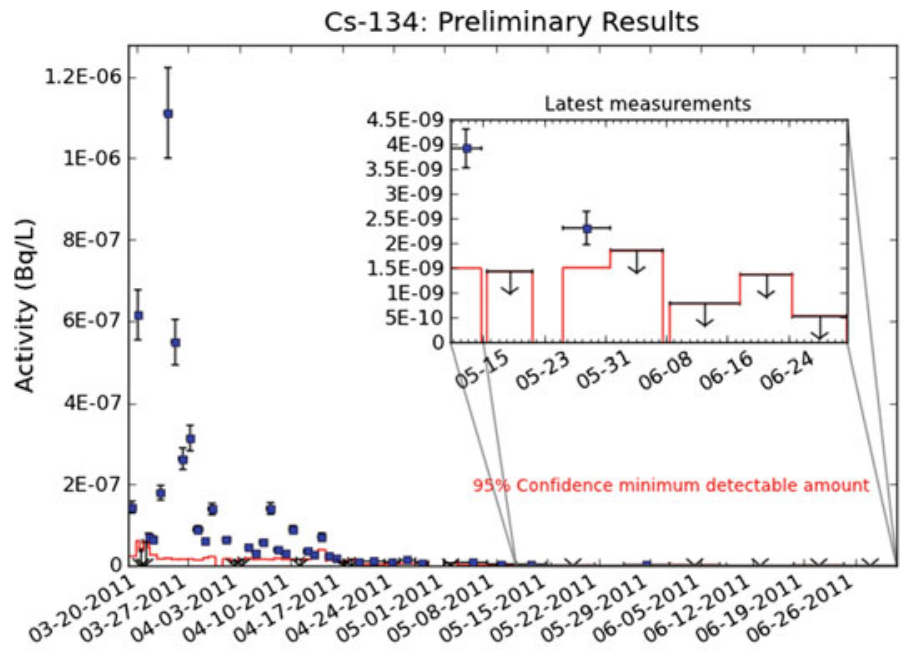

Date Collected

Fig. $6{ }^{137} \mathrm{Cs}$ and ${ }^{134} \mathrm{Cs}$ discrete filter air sampling just after Fukushima with first revision air sampler. The RAM system would have the ability to continuously sample events of this kind, capturing the transient response 


\section{Outreach (Heading A)}

Accessibility and transparency are vital to establishing trust in an outreach effort. The website allows the RadWatch activities to scale accessibility, by providing data in context about the naturally radioactive world we are living in. The strongest context for the RAM system is in the long time history over which we are tracking isotopes. In the future, a computed NORM dose-rate-variance could be used as an unavoidable dose band for putting excess dose risk in perspective. Transparency is imposed by the immediacy with which results are published, while maintaining good quality control.

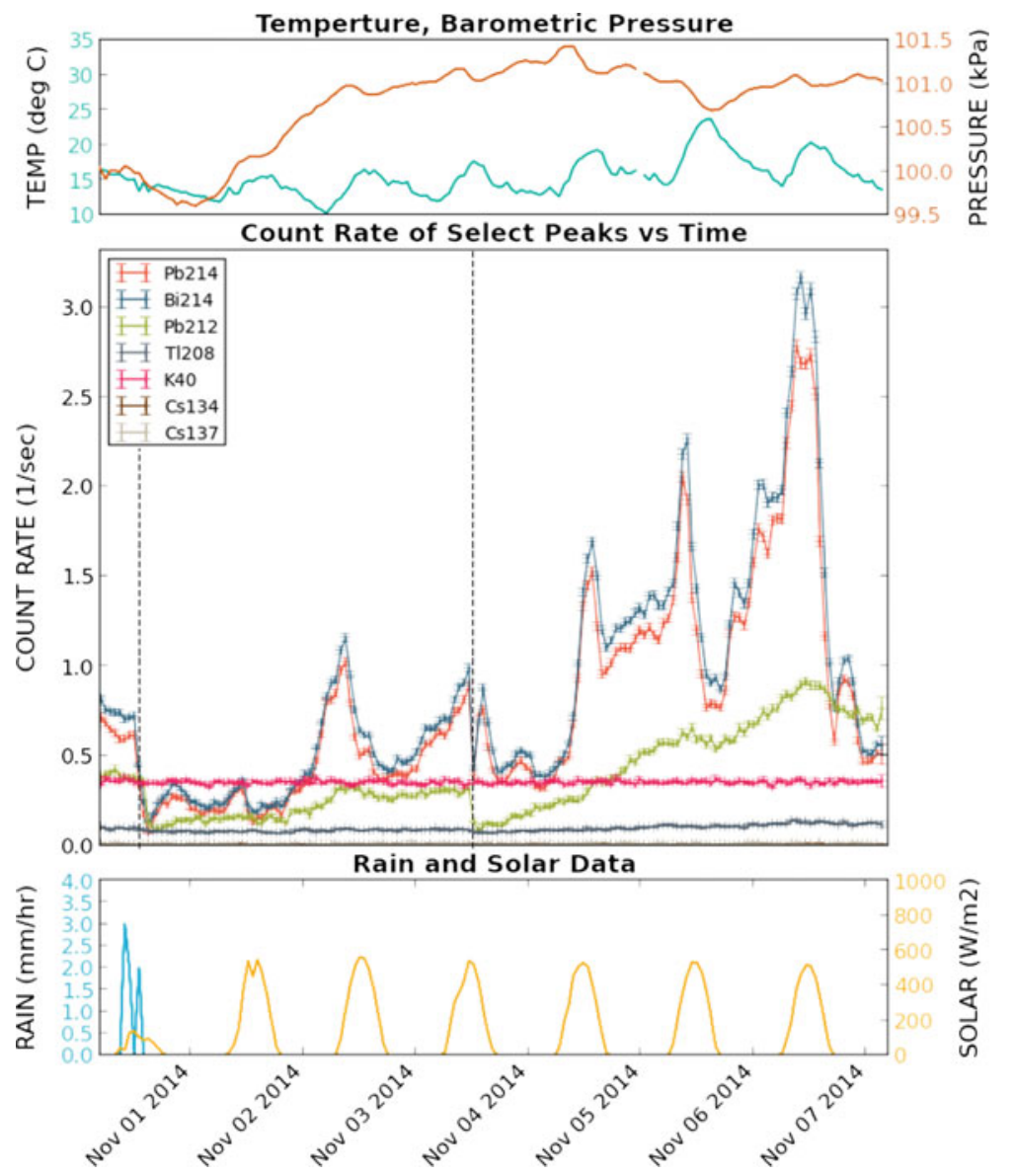

Fig. 7 [Middle] Net peak counts rate for 1 week. The natural background lines vary by as much as factors of 25. Observation of this variance is considerable. Dashed black lines indicate the filter exchange times. [Top and bottom] Meteorological data collected from the weather station just above the monitor. Currently the air monitor is down for upgrades to allow for deduction of weather trends 

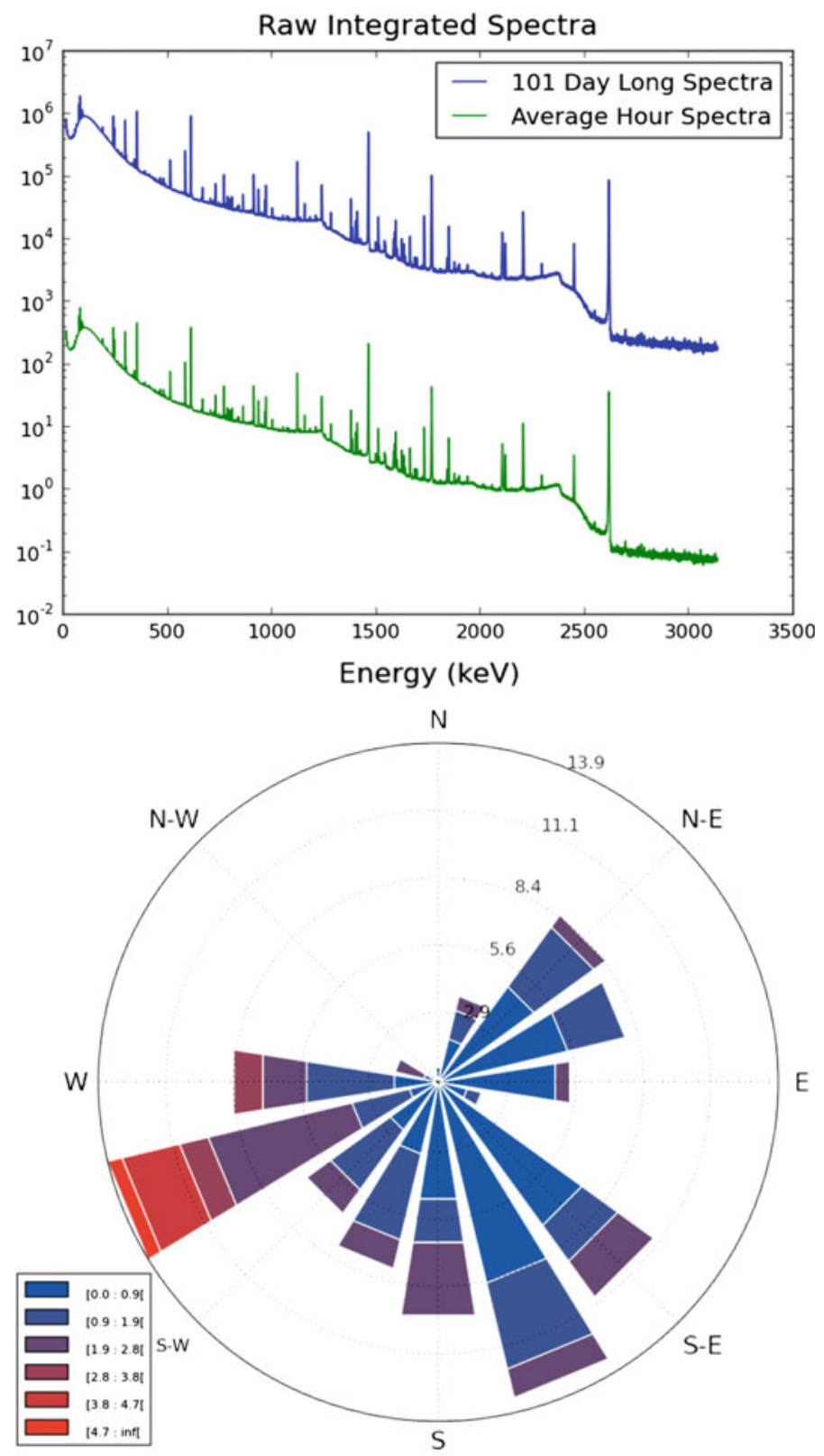

Fig. $8[T o p]$ A wind rose measured from the weather station. The most probable direction for wind was W-SW at about $14 \%$ of the time with gusts up to $4.7 \mathrm{~m} / \mathrm{s}+$. [Bottom] Integrated and average spectra from $100 \mathrm{~d}$ period 


\section{Preliminary Results/Status}

The air monitor provided data with a total downtime of about $72 \mathrm{~h}$ over the Feb to Dec 2014 time period. A sample of this data is provided in Fig. 7. One can observe factors of 25 variation in certain gamma ray lines. This defines the natural band of variation for these products in the air. More work is to be done to remove systematics from the data, with the caveat that isotope selection is a bandwidth filter. Planned upgrades will help achieve the optimum time resolution for radon concentration in the air. The optimum is defined by the rate kinetics with some simple assumptions about the isotope collection (Fig. 8).

\section{Conclusions}

A radiologically resilient society will depend on public data provided in context and transparently. We have demonstrated the operation of a high resolution spectroscopy system with accessible data to provide the public with the facts that the world is radioactive and that they concentration of natural radioactivity in the air varies considerably. The goal of this research is to eventually calculate an estimate of current dose rate. Concentration of background isotopes in the environment are incredibly useful for putting nuclear technologies and events in context, allowing the public and scientific community to weigh the risks and benefits associated with this field.

\section{Reference}

1. NCRP Report No. 160: Ionizing radiation exposure of the population of the United States 2009. J. Radiol. Prot. 29, 465

Open Access This chapter is licensed under the terms of the Creative Commons Attribution 4.0 International License (http://creativecommons.org/licenses/by/4.0/), which permits use, sharing, adaptation, distribution and reproduction in any medium or format, as long as you give appropriate credit to the original author(s) and the source, provide a link to the Creative Commons license and indicate if changes were made.

The images or other third party material in this chapter are included in the chapter's Creative Commons license, unless indicated otherwise in a credit line to the material. If material is not included in the chapter's Creative Commons license and your intended use is not permitted by statutory regulation or exceeds the permitted use, you will need to obtain permission directly from the copyright holder.

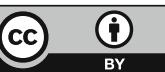

